\begin{tabular}{|c|l|}
\hline Title & Seasonality and regional productivity in the Spanish accommodation sector \\
\hline Author(s) & Saito, Hisamitsu; Romão, João \\
\hline Citation & $\begin{array}{l}\text { Tourism Management, 69, 180-188 } \\
\text { https://doi.org/40.1016/.tourman.2018.06.005 }\end{array}$ \\
\hline Issue Date & 2018-01-12 \\
\hline Doc URL & http://hdl.handle.net/2115/83762 \\
\hline Rights & $\begin{array}{l}\text { ○ 2018. This manuscript version is made available under the CC-BY-NC-ND 4.0 license } \\
\text { http://creativecommons.org/icenses/by-nc-nd/4.0/ }\end{array}$ \\
\hline Type & article (author version) \\
\hline File Information & manuscript_HUSCA P.pdf \\
\hline
\end{tabular}

Instructions for use 


\title{
Seasonality and Regional Productivity in the Spanish Accommodation Sector
}

\author{
Hisamitsu Saito* \\ Hokkaido University \\ Kita 9 Nishi 7, Kita-ku, Sapporo 0600809, Japan \\ saitoh@econ.hokudai.ac.jp \\ João Romão \\ University of Algarve \\ Gambelas Campus, Faculty of Economics \\ 8005-139 Faro, Portugal \\ jfromao@ualg.pt
}

\begin{abstract}
This study quantifies the impact of peak demand and seasonality on regional productivity in the Spanish accommodation sector. We then identify factors affecting seasonal fluctuations and their relative contributions to regional variations in seasonality. The results show that demand for accommodation in the peak season mainly determines productivity. Thus, improving a region's attractiveness as a tourist destination is most effective for tourism-based regional development. In addition, reducing seasonal variations has a non-negligible impact on productivity. A decomposition analysis reveals that providing climate-independent tourist attractions and attracting business travelers are effective in reducing seasonality.
\end{abstract}

Keywords: Tourism, Regional development, Productivity accounting

JEL Codes: Z32, D24, R11

* Corresponding author: saitoh@econ.hokudai.ac.jp

\section{Acknowledgment}

Saito acknowledges support from JSPS KAKENHI Grant Number 15K17042. Romão acknowledges support from Fundação para a Ciência e a Tecnologia and FEDER/COMPETE (grants UID/ECO/04007/2013 and SFRH/BPD/98938/2013). The authors are grateful for the helpful comments and suggestions from Masayuki Morikawa. 


\section{Seasonality and Regional Productivity in the Spanish Accommodation Sector}

\section{Introduction}

Tourism is the economic backbone in regions where the manufacturing sector accounts for a small percentage of overall income and employment (Lee and Brahmasrene 2013; Pratt 2015).

Lee and Chang (2008), for instance, find that tourism development-measured by the number of tourist arrivals or amount of tourism receipts-increases the total GDP per capita in non-OECD countries more than in OECD countries. Bojanic and Lo (2016) also conclude that total GDP per capita rises with tourism income, although heavy tourism reliance reduces its economic return. Therefore, exploring effective ways to improve tourism destination attractiveness, or to increase the number of tourists, has drawn much attention in academic and policy circles (Enright and Newton 2004; Mazanec et al. 2007).

However, policies that are well designed to improve tourism destination attractiveness might not lead to regional economic development if the resulting rise in tourism demand is centered on a particular season (Jang 2004; Vergori 2012). Combined with the fixed nature of capacity and resources in the tourism sector, such unevenness of tourism demand causes low capital utilization in off-peak periods. If the inefficient use of fixed capital significantly reduces the profitability of the sector, the consequently low returns on capital might result in an insufficient investment for the tourism facility to meet peak demand, sacrificing employment growth or tax revenue in the region (Murphy 1985, Koenig-Lewis and Bischoff 2005). 
Numerous studies have emphasized the negative effects of seasonality on tourism business management, but few studies have examined its quantitative impact (Park et al. 2016). Thus, the first contribution of this study is to quantify the economic impact of seasonality on the Spanish accommodation sector. Tourism in Spain, particularly in coastal areas, is subject to high seasonality (Parrilla et al. 2007). For instance, in 2014, the number of bed places used in offpeak periods in the Balearic Islands, a major sun and beach destination in Spain, was only 4 percent of the total bed-places provided in the peak season. Our estimation results provide empirical evidence on whether large seasonal fluctuations observed in those regions would reduce the performance of the accommodation sector. Based on the results, we argue whether attracting a sufficient number of tourists in the peak season could offset the negative impact of seasonality. If it is found to be insufficient, public investment in the tourism sector would be an option for its sustainable development (Mathieson and Wall 1982).

Reducing seasonality is an alternative for the tourism sector and public authorities. Earlier studies, as part of efforts to predict the effectiveness of policies that reduce seasonality, have identified two factors-natural and institutional—that primarily cause the seasonal fluctuations in tourism demand (BarOn 1975). Natural factors include temperature, weather, and sunlight hours, while institutional factors include school and religious holidays, and locally available activities. Baum and Hagen (1999) extend the list to include "business customs," "calendar effects," and "supply side constraints" as additional causes of seasonality. Policy 
instruments effective for each factor-proposed in BarOn (1975) and subsequent studies—are employed by local governments and businesses to reduce seasonality (Cellini and Rizzo 2012; Connell et al. 2015). The organization of special events and festivals, contra-seasonal pricing, and cultural tourism are well-known examples of such instruments (Parrilla et al. 2007; Figini and Vici 2012; Connell et al. 2015). Another option is to attract business travelers, who are less sensitive to natural factors (Garrod 2012).

Indeed, studies on the effectiveness of individual instruments in reducing seasonality are abundant. However, little attention has been paid to the relative contribution of each factor to regional variations in seasonality (Lundtorp et al. 1999; Nadal et al. 2004; Connell et al. 2015). By identifying the sources of seasonality, this study contributes to providing local governments and businesses with the information necessary for choosing the most effective instrument to reduce seasonal fluctuations in tourism demand.

The remainder of the paper is organized as follows. The conceptual framework and review of the relevant literature are presented in Section 2. We provide an overview of the tourism economy in Spain and its regions in Section 3. Section 4 develops the estimation models, while Section 5 describes the data and variable construction. Section 6 presents the estimation results, and Section 7 concludes with a summary of the results and policy implications. 


\section{Conceptual Framework}

A major concern about seasonality in the tourism sector is the inefficient use of fixed inputs in off-peak periods. Hence, quantifying its economic impact requires a performance measure that relates the amount of service produced by the sector to the amount of inputs used in production.

Productivity is a measure widely used for that purpose (Syverson 2011). In the tourism literature,

for instance, Terry (2016) argues that the hotel industry can mitigate the negative impact of seasonality by adjusting the number of temporary workers, in other words, numerical flexibility, and by internally transferring existing workers between tasks, or functional flexibility (see also Krakover 2000). Park et al. (2016) provide empirical evidence that this flexibility is key for labor productivity in UK hotels. Ortega and Chicón (2013) also conclude that seasonality does not reduce labor productivity in the Spanish hospitality industry.

However, labor productivity as employed in those studies is not an ideal measure for our objectives for the following two reasons. First, from the methodological perspective, labor productivity does not necessarily capture the true performance of the accommodation sector in off-peak periods because it does not consider the opportunity cost of fixed inputs, such as bedplaces, another key production factor in the accommodation sector. By contrast, total factor productivity (TFP) accounts for all production factors, including bed-places. Consequently, TFP is more relevant than labor productivity for evaluating the relative contribution of peak demand and seasonality to industry performance. 
Second, from the policy perspective, heavy reliance on labor flexibility does not necessarily contribute to the sustainable development of the sector and local economies. For example, Adler and Adler (2003) describe cases in which temporary workers leave the region for better opportunities because of employment instability and low earnings in the hotel industry. Partly due to this instability, the tourism sector faces difficulty securing qualified employees even in the peak season (Terkenli 2005; Terry 2016). Thus, in addition to labor flexibility, tourism authorities and businesses need to identify alternative policies that are effective for reducing seasonality. In this regard, the choice of productivity measure has important implications for the selection of optimal tourism policies. The flexible use of labor would considerably increase labor productivity (Park et al. 2016) but would not raise capital utilization in off-peak periods. Hence, the use of TFP turns our focus to exploring alternative policy instruments—other than labor flexibility—that are effective for reducing seasonality and improving productivity.

Next, the Gini coefficient is often employed in the tourism literature as a measure of seasonality (e.g., Fernández-Morales 2003; Nadal et al. 2004; Ortega and Chicón 2013). The Gini coefficient is defined based on the Lorenz curve, which plots the cumulative share of monthly overnight stays on the vertical axis and months ranked from the smallest to the largest number of monthly overnight stays on the horizontal axis. In a region with no seasonality, the Lorenz curve would be a 45-degree line. The Gini coefficient-obtained as twice the area 
between the line of no seasonality (45-degree line) and the observed Lorenz curve-varies between 0 and 1 , with its value increasing with the degree of seasonality. Figure 1 shows the Lorenz curve in the Balearic Islands in 2014 as an example. It shows that visitors to the islands are concentrated in the summer months from July to September, accounting for around 40 percent of the total number of visitors in 2014. The Gini coefficient in the Balearic Islands, represented as twice the shaded area, is 0.495 and is the largest among the Spanish regions.

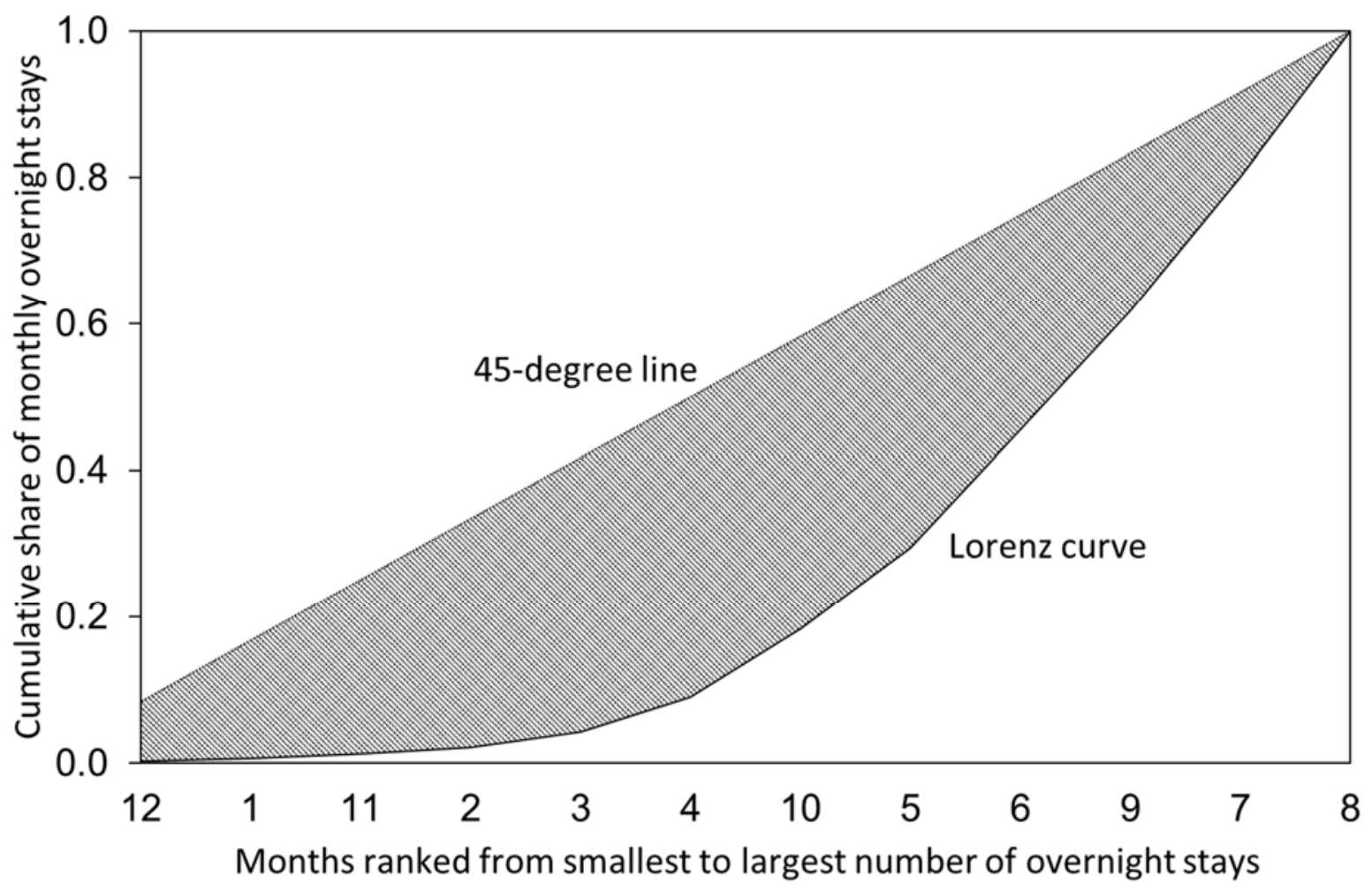

Source: INE, Hotel Occupancy Survey, 2014.

Figure 1: Seasonality in the Balearic Islands 


\section{Tourism Economy and Seasonality in Spain}

We employ data from the Spanish accommodation sector to examine the impact of seasonality on productivity, and to identify factors that can significantly reduce seasonality. Spain and its regions provide an interesting case to study the tourism economy and seasonality (Such and Zamora 2006). Located at the southern periphery of the European Union (EU), Spain's economy relies on tourism: the tourism sector accounted for 5.6 percent of GDP, 5.0 percent of employment, and 15.3 percent of exports in 2014, much higher than the European averages of 3.4 percent, 3.6 percent, and 5.6 percent, respectively (WTTC 2015).

More importantly for this study, regardless of its high seasonality, Spain ranks 4th among European countries in terms of capital investment in the tourism sector (WTTC 2015). The tourism sector attracted EUR 13.5 billion of capital investment in 2014, accounting for 6.9 percent of the total investment in Spain. As discussed in the introduction, the investment decision is made based on the return it is expected to generate. To keep attracting this high level of investment, it is critical to identify the extent to which seasonality reduces the performance of the sector, and to develop effective policies to reduce seasonality.

If we focus on its regions, Spain has several major tourist destinations: four NUTS 2 regions-the Canary Islands (1st), Catalonia (3rd), the Balearic Islands (4th), and Andalusia (8th) - are ranked in the top 10 among EU regions in terms of the number of overnight stays, according to the 2012 Eurostat data. However, seasonal fluctuations in tourism demand show 
large spatial variations, even within the major tourist destinations (Duro 2016). Regions along the Mediterranean Sea or the Atlantic Ocean tend to have large seasonal fluctuations, while Madrid, the capital of Spain, and the Canary Islands have the smallest ones (Figure 2). These findings motivate us to examine whether the large peak demand can offset the reduction in profitability that would be caused by large seasonal fluctuations in Catalonia, the Balearic Islands, or Andalusia.

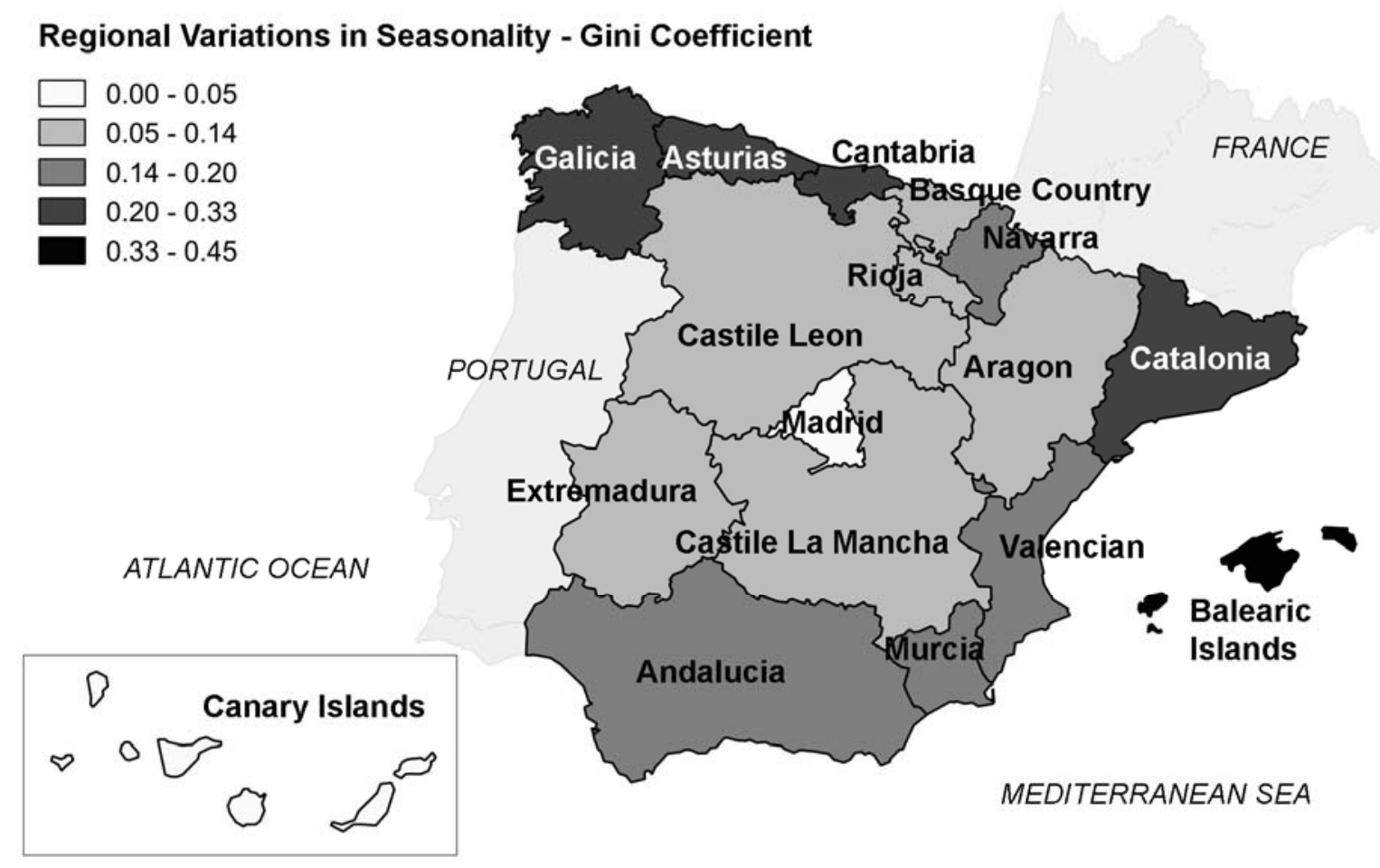

Source: INE, Hotel Occupancy Survey, various years.

Figure 2: Geographic Variations in Seasonality among NUTS 2 Regions in Spain

Next, such large spatial variations in seasonality could be attributed to various factors.

For example, both the Canary Islands and the Balearic Islands are popular tourist destinations, but the former has a subtropical climate, attracting sightseeing tourists for the whole year, while 
the latter has a Mediterranean climate, attracting the most tourists during the summer.

Identifying factors other than natural ones that can significantly reduce seasonal fluctuations has great policy importance for local governments and businesses in coastal regions. In contrast, Madrid attracts travelers with various - sightseeing and business-purposes all year round, which would cause the smallest seasonal fluctuations in tourism demand among the inland Spanish regions.

\section{Methodology}

\subsection{Regional Productivity and its Determinants}

Seasonality is supposed to reduce productivity in the accommodation sector because of the low capital utilization rate in off-peak periods. In Section 2, we discussed that TFP describes the technical relationship between output and all the inputs in production and that it is more relevant than labor productivity for measuring the effects of seasonality on the profitability of the sector. To obtain TFP, we consider the following regional-level production function (Planas et al. 2010):

$$
\begin{aligned}
Y_{r t} & =Z_{r t} L_{r t}^{\beta_{1}}\left(C U_{r t} K_{r t}\right)^{\beta_{2}} \exp \left(d_{r}+d_{t}+\eta_{r t}\right) \\
& =A_{r t} L_{r t}^{\beta_{1}} K_{r t}^{\beta_{2}} \quad \text { with } A_{r t} \equiv Z_{r t} C U_{r t}^{\beta_{2}} \exp \left(d_{r}+d_{t}+\eta_{r t}\right)^{\prime}
\end{aligned}
$$

where $r=1,2, \ldots, R$ denotes NUTS 2 regions and $t=1,2, \ldots, T$ denotes year. $Y_{r t}, L_{r t}$, and $K_{r t}$ represent the number of annual overnight stays, labor, and the number of bed-places, respectively.

Further, $Z_{r t}, C U_{r t}, d_{r}, d_{t}$, and $\eta_{r t}$, representing technology, capital utilization rate, NUTS 2 region and year fixed effects, and unanticipated shocks to output, respectively, constitute TFP, 
$A_{r t}$. Since $\beta_{2}>0$, Equation (1) clearly indicates that low capital utilization during off-peak periods, namely low $C U_{r t}$, reduces TFP in that region. After estimating the $\log$ form of Equation (1), the $\log$ of TFP in region $r$ and year $t$ is obtained as a residual:

(2) $\quad \ln A_{r t}=\ln Y_{r t}-\hat{\beta}_{1} \ln L_{r t}-\hat{\beta}_{2} \ln K_{r t}$, where ${ }^{\wedge}$ on parameters indicates regression estimates of the production function.

Three comments are in order here. First, TFP obtained in Equation (2) is considered quantity-based TFP because Equation (1) uses physical quantities as the output measure, rather than price-deflated revenues (Van Beveren 2012). As compared with revenue-based TFP, the use of quantity-based TFP does not exert price effects (De Loecker 2011). For example, the pricing behavior of hotels substantially varies across regions: prices in off-peak season tend to be lower in regions with strong seasonality due to contra-seasonal pricing (Saló et al. 2012).

If we employ revenue-based TFP, we cannot conclude whether a decline in measured productivity is attributable to low capital utilization in off-peak periods or to contra-seasonal pricing. Both factors can affect profitability but in different ways: low capital utilization affects the technical relationship between output and inputs but contra-seasonal pricing does not. Thus, distinguishing these two factors is important as the optimal policy to mitigate the impact of seasonality on profitability varies, depending on the underlying cause. By employing the quantity-based TFP, we can evaluate the extent to which seasonality reduces productivity of hotels through the inefficient use of capital in off-peak periods. Future studies, which examine 
the effects of seasonality on pricing behavior of hotels, can complement our study to assess the overall impact of seasonality on the profitability of the accommodation sector.

Next, following Benito et al. (2014) and Roget and González (2006), we use the number of bed-places as a proxy for capital stock because of data availability. It does not include buildings or machines, but it represents the most important production factor of the accommodation services. A drawback of this measure is that it does not reflect the quality differences of hotel rooms, which could potentially bias our TFP estimates: even if a hotel renovates its property, the amount of investment is not counted unless renovation changes the number of bed-places. Thus, the results should be interpreted with caution in this regard. Finally, material such as hotel amenities is not included in Equation (1) due to data availability. Section 5 describes the data used in the estimation of the production function in more detail.

Our first objective is to evaluate the extent to which peak demand and seasonality affect productivity of the accommodation sector. For that purpose, we estimate the following regional productivity model:

$$
\ln A_{r t}=\alpha_{0}+\alpha_{1} \ln \max _{r t}+\alpha_{2} \ln S_{r t}^{i}+d_{r}+d_{t}+\varepsilon_{r t}
$$

where $\max _{r t}$ is the maximum number of monthly overnight stays in region $r$ and year $t ; S_{r t}^{i}$ denotes seasonal fluctuations in tourism demand in region $r$ and year $t$; and the superscript $i=G, C$ represents the seasonality measure employed. We use two seasonality measures to 
check the robustness of our results to different specifications (Duro 2016): the Gini coefficient $(i=G)$ and the coefficient of variation $(i=C)$ of monthly overnight stays.

The maximum number of monthly overnight stays measures the region's attractiveness as a tourist destination. Stated differently, $\alpha_{1}>0$ indicates that improving tourism destination attractiveness contributes to regional economic development. Regarding seasonality, among regions facing the same level of peak demand $\left(\max _{r t}\right)$, those with large seasonal fluctuations will have lower capital utilization in off-peak periods, namely, lower annual productivity, than those with small fluctuations. As the measure of seasonality, for each region and year, we estimate the Gini coefficient and the coefficient of variation using the number of monthly overnight stays. Both measures take a large value in a region with large seasonal fluctuations, implying $\alpha_{2}<0$; that is, productivity should be lower in regions with larger values of the seasonality measure. Given TFP and parameter estimates of Equation (3), a comparison of productivity levels across regions can be undertaken as follows (Hall and Jones 1999):

$$
\frac{\tilde{A}_{r}}{\tilde{A}_{b}}=\left(\frac{m \tilde{a} x_{r}}{m \tilde{a} x_{b}}\right)^{\hat{\alpha}_{1}}\left(\frac{\tilde{S}_{r}^{i}}{\tilde{S}_{b}^{i}}\right)^{\hat{\alpha}_{2}} \exp \left(\hat{d}_{r}-\hat{d}_{b}+\overline{\hat{e}}_{r t}-\overline{\hat{e}}_{b t}\right),
$$

where ${ }^{\sim}$ and ${ }^{-}$on variables represent geometric and arithmetic means across years, respectively; $b$ denotes the base region; and $e$ is the residual from Equation (3). Equation (4) shows that the productivity gap between the $r$-th and $b$-th (base) regions can be decomposed into regional differences in peak demand and seasonality. Thus, numerical comparison of these factors yields each factor's contribution to regional productivity disparities. 


\subsection{Seasonality and its Determinants}

Our second objective is to identify factors affecting seasonality and quantify their contribution.

In doing so, we first estimate the following seasonal fluctuation model:

$$
\begin{array}{r}
\ln S_{r t}^{i}=\gamma_{0}+\gamma_{1} \ln \text { popden }_{r t}+\gamma_{2} \ln H H I_{r}+\gamma_{3} \ln \left(1+h r t g_{r t}\right)+\gamma_{4} \ln m u s_{r t} \\
+\gamma_{5} \ln s h f_{r t}+\gamma_{6} \ln t v l r_{r t}+d_{R}+d_{t}+\omega_{r t}
\end{array}
$$

where popden $_{r t}, H H I_{r}, h r t g_{r t}$, mus $_{r t}, s h f_{r t}, t v l r_{r t}, d_{R}$, and $d_{t}$ denote population density, the

Herfindahl-Hirschman Index, the number of World Heritage Sites, the number of museums, the share of foreign travelers, the number of both domestic and foreign travelers, and NUTS 1 region and year fixed effects. NUTS 2 region fixed effects are not used in Equation (5) because most regional variables show little variation across time periods or are time-invariant (see Section 5).

Because the number of business travelers is not available in our dataset, we use popden $_{r t}$ and $H H I_{r}$ as proxies, both of which measure the degree of urbanization of region $r$. The underlying assumption is that the more spatial-concentration of economic activity there is in a region, the more business travelers will visit that region. The urban economics literature (e.g., Combes et al. 2008) argues that the attractiveness of urban areas for business location is mainly determined by the following two characteristics: the spatial density of economic activity (Ciccone and Hall 1996; Ciccone 2002) and industrial diversity (Jacobs 1969; Henderson et al. 1995). HHI takes a value between 0 and 1, with its value decreasing as the industrial structure in a region becomes more diverse. Consequently, the more intense (large popden $r$ ) or the more 
diverse (low $\mathrm{HHI}_{\mathrm{r}}$ ) economic activities in a region are, the more business travelers will visit the region constantly throughout the year, implying that $\gamma_{1}<0$ and $\gamma_{2}>0$.

Having weather- or climate-independent tourist attractions, such as World Heritage Sites and museums, within a region should be effective for attracting travelers all year round. Unless the resulting tourism demand is not centered on the peak season, the overall impact on seasonality of having those attractions will be negative: $\gamma_{3}<0$ and $\gamma_{4}<0$. Attracting travelers from various countries helps level out seasonality because foreign travelers follow their own holiday calendars, implying that $\gamma_{5}<0$ (Fernández-Morales and Mayorga-Toledano 2008; Morikawa 2016). Finally, regions vary in terms of economic and area size. As region size is likely positively correlated with regional variables such as the number of museums, parameters estimated without controlling for region size would be biased unless region size is uncorrelated with seasonality. NUTS 2 region fixed effects, such as those in Equation (3), could control for differences in region size but they are not included in Equation (5). Instead, the total number of travelers in (5), reflecting the region's overall size of tourism activities in each year, will do so.

Note that most of the factors that determine the level of seasonality in tourism demand are incorporated into Equation (5): popden $_{r t}$ and $H H I_{r}$ examine the effects of business tourism (business customs) on seasonality; hrtg $_{r t}$ and $m u s_{r t}$, which count the number of locally available activities, are considered as institutional factors; $s h f_{r t}$ indicates whether calendar effects can be mitigated by attracting more foreign travelers; and region fixed effects are included to correct for 
unobserved and time-invariant natural factors common across neighboring regions, such as climate and natural advantages of the location as a tourist destination.

After estimating Equation (5), we identify the contribution of each regional factor to the differences in the level of seasonality between regions by applying the same decomposition technique used to derive Equation (4):

$$
\begin{aligned}
& \frac{\tilde{S}_{r}^{i}}{\tilde{S}_{b}^{i}}=\left(\frac{p^{2} \tilde{p} \operatorname{den}_{r}}{{\text { po } \tilde{p} d e n_{b}}}\right)^{\hat{\gamma}_{1}}\left(\frac{H \tilde{H} I_{r}}{H \tilde{H} I_{b}}\right)^{\hat{\gamma}_{2}}\left(\frac{1+h \tilde{r} t g_{r}}{1+h \tilde{r} t g_{b}}\right)^{\hat{\gamma}_{3}}\left(\frac{m \tilde{u} s_{r}}{m \tilde{u} s_{b}}\right)^{\hat{\gamma}_{4}}, \\
& \times\left(\frac{s \tilde{h} f_{r}}{s \tilde{h} f_{b}}\right)^{\hat{\gamma}_{s}}\left(\frac{t \tilde{v} l r_{r}}{t \tilde{v} l r_{b}}\right)^{\hat{\gamma}_{6}} \exp \left(\hat{d}_{R}-\hat{d}_{B}+\overline{\hat{w}}_{r t}-\overline{\hat{w}}_{b t}\right){ }^{\prime}
\end{aligned}
$$

where $w$ is the residual from Equation (5). Note that each factor's contribution to regional productivity disparities $\left(\tilde{A}_{r} / \tilde{A}_{b}\right)$ can be obtained by raising the corresponding term in Equation (6) to the power of $\hat{\alpha}_{2}$.

\section{Data}

Our sample consists of time-series data for 2001-2014 for all NUTS 2 regions in Spain, except Ceuta and Melilla. These two regions are Spanish autonomous cities located on the north coast of Africa. Thus, regional variables cannot be compared directly between these two cities and other NUTS 2 regions. For instance, the very small land area in the former yields extremely high population density.

Data on the accommodation sector-the number of overnight stays, labor, and the number of bed-places-are from the Hotel Occupancy Survey of the National Statistics Institute 
(INE). Data on the number of travelers and the share of foreign travelers are obtained from the same data source. This monthly survey is carried out for every hotel establishment in Spain. Data on the number of monthly overnight stays are used to estimate seasonal fluctuations in tourism demand for each year, and to obtain the number of annual overnight stays. Labor is measured as the annual average of monthly employment levels for a given year. By contrast, the number of bed-places is defined as the maximum number of bed-places within a year. To take account of the low capital utilization rate in off-peak periods, bed-places not used during these periods should be counted when constructing the variable.

Regional population is from the Official Population Figures of the Spanish Municipalities, INE. The Herfindahl-Hirschman Index in a region is obtained as the sum of the squared employment shares of the NACE three-digit industrial sectors in the region using the 2001 Population and Housing Census, INE. The number of museums is obtained from the Museums and Collections Statistics in Spain, INE. Any type of museums, for example, fine arts, science and technology, ethnography, and anthropology, are covered in the survey. As this is a biennial study, the number of museums for the non-surveyed years is linearly interpolated between the 2 surveyed years. Finally, the number of World Heritage Sites is from the UNESCO World Heritage List (http://whc.unesco.org/en/list). The summary statistics of the variables are presented in Table 1. 
Table 1: Summary Statistics

\begin{tabular}{|c|c|c|c|c|c|}
\hline Variable & Unit & Mean & Std. deviation & $\begin{array}{l}\mathrm{CV} \text { across } \\
\text { regions }\end{array}$ & CV across time \\
\hline $\begin{array}{l}\text { Annual overnight stays } \\
(Y / 1,000,000)\end{array}$ & Number & 15.566 & 18.468 & 1.214 & 0.091 \\
\hline Labor $(L / 1,000)$ & Number & 10.753 & 11.363 & 1.083 & 0.111 \\
\hline Bed-places $(K / 1,000)$ & Number & 94.253 & 102.904 & 1.118 & 0.102 \\
\hline $\begin{array}{l}\text { Maximum of monthly } \\
\text { overnight stays in a year } \\
(\max / 1,000,000)\end{array}$ & Number & 2.242 & 2.855 & 1.301 & 0.097 \\
\hline $\begin{array}{l}\text { Gini coefficient of monthly } \\
\text { overnight stays }\left(S^{G}\right)\end{array}$ & Index, $0-1$ & 0.191 & 0.103 & 0.555 & 0.101 \\
\hline $\begin{array}{l}\text { Coefficient of variation of } \\
\text { monthly overnight stays }\left(S^{C}\right)\end{array}$ & Number & 0.362 & 0.198 & 0.560 & 0.101 \\
\hline Population density (popden) & Number $/ \mathrm{km}^{2}$ & 159.214 & 173.924 & 1.120 & 0.044 \\
\hline $\begin{array}{l}\text { Herfindahl-Hirschman Index } \\
(H H I)\end{array}$ & Index, $0-1$ & 0.028 & 0.007 & 0.250 & 0.000 \\
\hline $\begin{array}{l}\text { Number of World Heritage } \\
\text { Sites (hrtg) }\end{array}$ & Number & 2.933 & 1.899 & 0.666 & 0.104 \\
\hline Number of museums (mus) & Number & 79.286 & 54.238 & 0.694 & 0.164 \\
\hline $\begin{array}{l}\text { Share of foreign travelers } \\
(\operatorname{shf})\end{array}$ & Index, $0-1$ & 0.311 & 0.208 & 0.686 & 0.084 \\
\hline $\begin{array}{l}\text { Number of travelers } \\
(t v l r / 1,000,000)\end{array}$ & Number & 4.641 & 4.471 & 0.981 & 0.094 \\
\hline
\end{tabular}

Note: CV across regions measures the coefficient of variation of each variable across regions for each year. Then, obtained coefficients are averaged over years. Similarly, CV across time measures the variation across time for each region. Then, obtained coefficients are averaged over regions.

Sources: INE, Hotel Occupancy Survey, various years.

INE, Museums and Collections Statistics in Spain, various years.

INE, Official Population Figures of the Spanish Municipalities, various years.

INE, 2001 Population and Housing Census.

UNESCO, World Heritage List.

In addition to mean and standard deviation, Table 1 shows the mean of the coefficient of variation for each variable across regions or time to see how much the variation in each variable is attributed to cross-sectional and time-series variations. Three comments can be made here.

First, time-series variations are smaller than cross-sectional ones, implying time persistence in variables. However, this should not be a critical issue as our main objective is to identify factors affecting regional, that is, cross-sectional variations in productivity and seasonality. Second, due 
to the relatively long estimation periods, time-series variations of the numbers of museums and World Heritage Sites—considered relatively time-invariant in the short run — are not small when compared to the variations of other regional factors. In other words, local governments and business are able to change the number of museums and World Heritage Sites, at least in the long run. Finally, the Herfindahl-Hirschman Index shows no time-variation because of data availability.

Table 2: Regional Variations in Seasonality

\begin{tabular}{lcc}
\hline Region & Gini coefficient & Coefficient of variation \\
\hline Andalusia & 0.203 & 0.376 \\
Aragon & 0.118 & 0.236 \\
Asturias & 0.286 & 0.569 \\
Balearic Islands & 0.457 & 0.855 \\
Basque Community & 0.148 & 0.277 \\
Canary Islands & 0.055 & 0.105 \\
Cantabria & 0.331 & 0.646 \\
Castile-La Mancha & 0.105 & 0.196 \\
Castile-Leon & 0.145 & 0.270 \\
Catalonia & 0.300 & 0.560 \\
Extremadura & 0.132 & 0.248 \\
Galicia & 0.250 & 0.491 \\
La Rioja & 0.142 & 0.264 \\
Madrid & 0.056 & 0.105 \\
Navarre & 0.178 & 0.329 \\
Region of Murcia & 0.163 & 0.301 \\
Valencian Community & 0.173 & 0.321 \\
\hline
\end{tabular}

Note: Seasonal fluctuations are averaged over the estimation periods.

Table 2 shows the regional variations in seasonality. Both the Gini coefficient and the coefficient of variation yield a similar pattern of regional seasonality ranking: seasonal fluctuations are largest in the Balearic Islands and smallest in the Canary Islands and Madrid. 
Indeed, the Spearman's rank correlation coefficient between the two alternative measures of seasonality is 0.995 .

\section{Estimation Results}

\subsection{Determinants of Productivity}

The parameter estimates of the regional-level production function (Equation 1) are presented in

Table 3. The coefficients of both labor and the number of bed-places are positive and statistically significant at the 1 percent level. Based on the parameter estimates in Table 3 , the TFP by NUTS 2 regions and years is obtained to quantitatively examine the impact of peak demand and seasonality on the TFP (Equation 3).

Table 3: Parameter Estimates of the Production Function

\begin{tabular}{lcc}
\hline Variable & Coefficient & Std. error \\
\hline Labor $(\ln L)$ & $0.522^{* * * *}$ & 0.086 \\
Number of bed-places $(\ln K)$ & $0.414^{* * *}$ & 0.105 \\
NUTS 2 region fixed effects $\left(d_{r}\right)$ & \multicolumn{2}{c}{ Yes } \\
Year fixed effects $\left(d_{t}\right)$ & \multicolumn{2}{c}{ Yes } \\
F value & \multicolumn{2}{c}{11386.75} \\
R-squared & 0.999 \\
Observations & 238 \\
\hline N & \multicolumn{2}{c}{238} \\
\hline
\end{tabular}

Note: $* * *$ indicates statistical significance at the 1 percent level. The dependent variable is the number of annual overnight stays. Standard errors are heteroskedasticity consistent.

Recent studies such as Ortega and Chicón (2013) and Gómez-Calero et al. (2014) apply

GMM estimation to a model like Equation (3) to address the endogeneity problems. Following their methodology, we instrumented the first-differenced explanatory variables in Equation (3) by their levels in year $t-2$ and $t-3$. However, the estimated Kleibergen-Paap statistic was 
0.332, indicating these instruments were too weak to obtain consistent estimates (Wooldridge 2010). Hence, we report the OLS estimates in Table 4. We believe the OLS estimator is consistent for the following reason. In general, the destination of a trip is determined according to local attractions and thus, staying in a hotel is not usually the main objective of the trip.

Consequently, productivity of local hotels is not likely to affect peak demand or seasonality in a region significantly, implying that these two variables are orthogonal to unobserved productivity shocks.

Table 4: Determinants of Regional Productivity

\begin{tabular}{lcccc}
\hline & \multicolumn{2}{c}{ Gini coefficient $(i=G)$} & \multicolumn{2}{c}{ Coefficient of variation $(i=C)$} \\
\cline { 2 - 5 } Variable & $(1)$ & $(2)$ & $(3)$ & $(4)$ \\
\hline Max of monthly overnight stays & $0.498^{* * *}$ & $0.366^{* * *}$ & $0.519^{* * *}$ & $0.393^{* * *}$ \\
$(\ln$ max $)$ & $(0.034)$ & $(0.044)$ & $(0.034)$ & $(0.046)$ \\
Seasonal fluctuations & $-0.189^{* * *}$ & $-0.116^{* * *}$ & $-0.215^{* * *}$ & $-0.145^{* * *}$ \\
$\left(\ln S^{i}\right)$ & $(0.035)$ & $(0.034)$ & $(0.035)$ & $(0.036)$ \\
TFP in $t-1$ & & $0.371^{* * *}$ & & $0.346^{* * *}$ \\
$\left(\ln A_{r t-1}\right)$ & & $(0.069)$ & & $(0.070)$ \\
NUTS 2 region fixed effects $\left(d_{r}\right)$ & Yes & Yes & Yes & Yes \\
Year fixed effects $\left(d_{t}\right)$ & Yes & Yes & Yes & Yes \\
F value & 567.24 & 812.68 & 579.95 & 837.75 \\
R-squared & 0.984 & 0.988 & 0.985 & 0.988 \\
Observations & 238 & 221 & 238 & 221 \\
\hline
\end{tabular}

Note: $* * *$ indicates statistical significance at the 1 percent level. The dependent variable is total factor productivity. Heteroskedasticity-consistent standard errors are in parentheses.

Columns (1) and (3) of Table 4 show the estimation results using the Gini coefficient and the coefficient of variation as the measure of seasonality, respectively. In both cases, the parameter estimates are statistically significant and take the expected sign. Moreover, they are quantitatively similar between the cases. Productivity increases by approximately 0.5 and 0.2 
percent for every percentage increase in peak demand $\left(\max _{r t}\right)$ and for every percentage decline in seasonality $\left(S_{r t}^{i}\right)$, respectively. Stated differently, productivity in the Spanish accommodation sector can be enhanced by attracting more travelers in the peak season and by limiting the reduction in the number of tourists in off-peak periods as much as possible.

Columns (2) and (4) of Table 4 consider the dynamic relationship between productivity and regional variables. In the dynamic panel data framework, because of the correlation between the lagged dependent variable and the error term, the OLS estimates are inconsistent. However, as our panel's cross-sectional dimension is relatively small (17 NUTS-2-regions) compared to the time dimension (14 years), the panel GMM estimator such as Arellano and Bond (1991) did not perform satisfactorily. Therefore, we employ the least squares dummy variable (LSDV) estimator following Roodman (2009), who argues that the dynamic panel bias arising in the LSDV estimator becomes insignificant with an increase in the time dimension.

From column (2) of Table 4, the long-run impact of peak demand and seasonality on productivity is $0.582(=0.366 /(1-0.371))$ and $-0.184(=-0.116 /(1-0.371))$, respectively. Note that these values are quantitatively similar to those in column (1). This is confirmed by comparing column (3) and the long-run impact obtained from column (4) as well. Consequently, the relationship between productivity and peak demand and seasonality are robust in the dynamic panel framework. 


\subsection{Quantitative Impact of Seasonality on Productivity}

Productivity in each region relative to the base region-Castile-Leon-is presented in descending order in the second column of Table 5. We choose Castile-Leon as the base since the accommodation sector in that region has the median level of productivity in Spain. The maximum and minimum of productivity at the bottom of the table indicate that regional disparities in productivity, varying between 0.82 and 1.88, are very large. The highest productivity is concentrated in major tourist destinations: the Canary Islands and coastal regions along the Mediterranean Sea (e.g., the Balearic Islands, the Valencian Community, and Catalonia). By contrast, productivity tends to be low in inland Spain or in regions along the Atlantic Ocean (e.g., Cantabria, Castile-La Mancha, and Extremadura).

Having chosen Castile-Leon as the base region, we next decompose, as in Equation (4), each region's relative productivity into the components in the third to fifth columns of Table 5. Stated differently, the product of the last three columns of Table 5-the maximum number of monthly overnight stays, seasonal fluctuations, and regional fixed effects and residuals-yields relative productivity in column 2. Because both the Gini coefficient and the coefficient of variation yield similar results, we present the results based on the Gini coefficient in Table 5.

Overall, our decomposition shows that the maximum number of monthly overnight stays, varying between 0.35 and 3.30 , is the most important determinant of regional productivity disparities in Spain. For instance, both regions along the Mediterranean Sea (i.e., the Balearic 
Islands and Catalonia) and those along the Atlantic Ocean (i.e., Asturias and Cantabria) show large seasonality but greater peak demand in the former regions leads to higher productivity compared to the latter regions. In other words, peak demand is not sufficient to offset the effects of seasonality on productivity in the latter regions. The results suggest that increasing the number of tourists in the peak season—by improving the region's attractiveness as a tourist destination-could compensate for low capital utilization in the off-peak periods.

Table 5: Decomposition of Regional Productivity Disparities

\begin{tabular}{lcccc}
\hline Region & Productivity & $\begin{array}{c}\text { Max of monthly } \\
\text { overnight stays }\end{array}$ & $\begin{array}{c}\text { Seasonal } \\
\text { fluctuations }\end{array}$ & $\begin{array}{c}\text { Region fixed effects } \\
\text { and residuals }\end{array}$ \\
\hline Canary Islands & 1.88 & 2.47 & 1.20 & 0.63 \\
Balearic Islands & 1.82 & 3.30 & 0.80 & 0.69 \\
Valencian Community & 1.69 & 1.88 & 0.97 & 0.93 \\
Catalonia & 1.59 & 2.84 & 0.87 & 0.64 \\
Andalusia & 1.48 & 2.56 & 0.94 & 0.62 \\
Madrid & 1.40 & 1.34 & 1.20 & 0.87 \\
Basque Community & 1.11 & 0.76 & 1.00 & 1.47 \\
Region of Murcia & 1.09 & 0.62 & 0.98 & 1.78 \\
Castile-Leon & 1.00 & 1.00 & 1.00 & 1.00 \\
Aragon & 1.00 & 0.80 & 1.04 & 1.20 \\
La Rioja & 0.99 & 0.35 & 1.00 & 2.78 \\
Galicia & 0.98 & 1.22 & 0.90 & 0.89 \\
Asturias & 0.96 & 0.81 & 0.88 & 1.35 \\
Cantabria & 0.95 & 0.76 & 0.86 & 1.47 \\
Navarre & 0.94 & 0.47 & 0.96 & 2.07 \\
Castile-La Mancha & 0.92 & 0.64 & 1.06 & 1.35 \\
Extremadura & 0.82 & 0.52 & 1.02 & 1.56 \\
\hline Max & 1.88 & 3.30 & 1.20 & 2.78 \\
Min & 0.82 & 0.35 & 0.80 & 0.62 \\
Max/Min & 2.29 & 9.34 & 1.49 & 4.52 \\
\hline Na Va
\end{tabular}

Note: Values are relative to those in Castile-Leon, the base region. Seasonal fluctuations are estimated by the Gini coefficient. 
The contribution of seasonality to regional productivity gaps, which varies between 0.80 and 1.20 , is not as large as the contribution of peak demand, but its impact is still non-negligible. Large fluctuations observed in major tourist destinations result in a reduction in productivity in those regions. For example, relative productivity in the Balearic Islands would increase from 1.82 to $2.28(=3.30 \times 1 \times 0.69)$ if seasonal fluctuations in that region had the same level of fluctuations as the base region. Finally, unobserved regional characteristics, measured by regional fixed effects and residuals, also significantly contribute to regional productivity disparities.

\subsection{Determinants of Seasonality}

Table 6 provides the parameter estimates of the seasonal fluctuation model (Equation 5). The Gini coefficient and the coefficient of variation are regressed on regional factors in columns (1) and (3), respectively. Most of the coefficients, except for those on the Herfindahl-Hirschman Index $\left(H H I_{r}\right)$ and the share of foreign travelers $\left(s h f_{r t}\right)$, take the expected sign and are statistically significant at the 1 percent level. In addition, like Table 4 , the parameter estimates are quantitatively similar between the two cases. Note that we add value 1 when we take the log of the number of World Heritage Sites because one region did not have any site for the first five years. We have confirmed the robustness of our results by excluding those five observations and using $\ln h r t g_{r t}$ instead of $\ln \left(1+h r t g_{r t}\right)$. 
Table 6: Determinants of Seasonality

\begin{tabular}{lcccc}
\hline & \multicolumn{2}{c}{ Gini coefficient } & \multicolumn{2}{c}{ Coefficient of variation } \\
\cline { 2 - 5 } Variable & $(1)$ & $(2)$ & $(3)$ & $(4)$ \\
\hline Population density & $-0.082^{* * *}$ & $-0.077^{* * *}$ & $-0.096^{* * *}$ & $-0.090^{* * *}$ \\
(lnpopden) & $(0.031)$ & $(0.031)$ & $(0.031)$ & $(0.031)$ \\
Herfindahl-Hirschman Index & -0.026 & 0.004 & 0.010 & 0.047 \\
(lnHHI) & $(0.088)$ & $(0.085)$ & $(0.092)$ & $(0.087)$ \\
World Heritage Site & $-0.131^{* * *}$ & $-0.057^{*}$ & $-0.142^{* * *}$ & -0.052 \\
(ln $(1+h r t g)$ ) & $(0.049)$ & $(0.035)$ & $(0.051)$ & $(0.035)$ \\
Museum & $-0.202^{* * *}$ & $-0.156^{* * *}$ & $-0.197^{* * *}$ & $-0.142^{* * *}$ \\
(lnmus) & $(0.025)$ & $(0.016)$ & $(0.026)$ & $(0.017)$ \\
Share of foreign travelers & $0.454^{* * *}$ & $0.561^{* * *}$ & $0.416^{* * *}$ & $0.546^{* * *}$ \\
(lnshf) & $(0.073)$ & $(0.044)$ & $(0.075)$ & $(0.047)$ \\
Number of travelers & $0.100^{* *}$ & & $0.122^{* * *}$ & \\
(lntvlr) & $(0.047)$ & & $(0.049)$ & \\
NUTS 1 region fixed effects $\left(d_{R}\right)$ & Yes & Yes & Yes & Yes \\
Year fixed effects $\left(d_{t}\right)$ & Yes & Yes & Yes & Yes \\
F value & 198.10 & 195.65 & 183.20 & 176.54 \\
R-squared & 0.942 & 0.940 & 0.939 & 0.937 \\
Observations & 238 & 238 & 238 & 238 \\
\hline
\end{tabular}

Note: ${ }^{*}, * *$ and $* * *$ indicate statistical significance at the 10 percent, 5 percent, and 1 percent levels, respectively. The first row indicates the dependent variable. Heteroskedasticity-consistent standard errors are in parentheses.

An increase in population density $\left(\right.$ popden $_{r t}$ ) reduces seasonality, implying that agglomeration of economic activities attracts business travelers to a region constantly throughout the year. Similarly, increasing the number of World Heritage Sites $\left(h_{r t g}\right)$ or museums $\left(\right.$ mus $\left._{r t}\right)$ within a region is an effective tool to raise the number of tourists in the off-peak periods. By contrast, seasonal fluctuations tend to become large as the number of travelers $\left(t v l r_{r t}\right)$ increases.

The positive impact on seasonality is further accelerated if the share of foreign travelers rises.

The unexpected sign on the share of foreign travelers might indicate that they are more likely than domestic travelers to choose the best season for sightseeing. Fernández-Morales and 
Mayorga-Toledano (2008) also observe that attracting foreign travelers may enlarge seasonality in the region, depending on the countries of origin of the tourists.

Finally, the multicollinearity issue should be addressed here. In the presence of multicollinearity, the OLS estimator is consistent but the obtained parameter estimates might be insignificant due to large standard errors. In our case, the coefficients on the HerfindahlHirschman Index is insignificant, as shown in Table 6 . To check whether this insignificant sign is due to multicollinearity, we re-estimate the model by excluding the number of travelers, which has the highest variance inflation factor (VIF) value and is strongly correlated with other explanatory variables (Table 7). The estimation results in columns (2) and (4) of Table 6 are quantitatively and qualitatively similar to those in (1) and (3), suggesting that multicollinearity is unlikely to be the cause of the insignificant sign on the Herfindahl-Hirschman Index. We avoid further reduction of variables as it would lead to omitted variable bias.

Table 7: Correlation Matrix and Variance Inflation Factor

\begin{tabular}{lccccccr}
\hline Variable & lnpopden & $\ln H H I$ & $\ln (1+h r t g)$ & $\operatorname{lnmus}$ & $\operatorname{lnshf}$ & $\ln t v l r$ & VIF \\
\hline Population density & 1 & & & & & & 14.95 \\
Herfindahl-Hirschman Index & -0.20 & 1 & & & & & 6.97 \\
World Heritage Site & -0.19 & 0.03 & 1 & & & & 7.84 \\
Museum & 0.13 & 0.08 & 0.59 & 1 & & & 7.18 \\
Share of foreign travelers & 0.68 & 0.07 & 0.18 & 0.32 & 1 & 17.29 \\
Number of travelers & 0.49 & 0.08 & 0.60 & 0.72 & 0.78 & 1 & 27.23 \\
\hline
\end{tabular}




\subsection{Quantitative Impact of Regional Factors on Seasonality}

Based on the parameter estimates in Table 6, we then explore the effectiveness of alternative strategies to mitigate the negative effects of seasonality on productivity. The second column of Table 8 shows seasonal fluctuations - measured by the Gini coefficient-in a region relative to the base region, Castile-Leon. Note that to be consistent with Table 5, regions are listed in descending order of productivity in Table 8 and the results do not change if we use the coefficient of variation as the measure of seasonality.

As discussed in Section 3, seasonal fluctuations are larger in coastal regions than inland regions. Seasonal fluctuations in column 2 of Table 8 are decomposed into factors according to Equation (6). As in Table 5, seasonal fluctuations in a region relative to the base region in column 2 can be obtained as the product of the last seven columns of Table 8 . Population density, namely, agglomeration of economic activities within a region, helps reduce seasonal fluctuations. Its effect is prominent in high-productivity regions. For example, because of Madrid's large population density, seasonal fluctuations in the region are reduced by 24 percent compared to the base region, if all other factors were to take the same values between Madrid and the base region. In addition, climate-independent tourist attractions-World Heritage Sites and museums-have a large impact on seasonality. Consistent with Cuccia and Rizzo (2011) and Cuccia et al. (2016), the impact of museums is more remarkable than those of World Heritage Sites. Lack of this kind of tourist attraction enlarges seasonal fluctuations in the top 
two regions (the Canary Islands and the Balearic Islands) and in low-productivity regions. For instance, if the Balearic Islands were to have the same number of museums as the base region, its seasonal fluctuations would be reduced from 3.16 to $2.57(=0.85 \times 0.99 \times 1.17 \times 1 \times 1.95 \times 1.07$ $\times 1.25)$.

On the other hand, attracting foreign travelers is not a valid instrument for reducing seasonality. Rather, according to the seventh column of Table 8 , it is one of the main causes of seasonal fluctuations in Spain. Another important cause of seasonality is natural factors, represented as "Regional fixed effects and residuals" in Table 8. A comparison between the Canary Islands and the Balearic Islands highlights the role of natural factors in seasonality. Seasonal fluctuations are the largest in the Balearic Islands and the smallest in the Canary Islands (second column of Table 8). Interestingly, however, all factors except the natural one show almost the same contribution to seasonality in both regions (Table 8). In other words, the difference in natural factors-a subtropical climate in the Canary Islands and a Mediterranean climate in the Balearic Islands-is the only factor characterizing the remarkable difference in seasonality between the two regions.

In summary, the number of museums, the share of foreign tourists, and natural factors mainly determine regional variations in seasonality in Spain. In addition, population density and the number of World Heritage Sites have a moderate impact on seasonality. 
Table 8: Decomposition of Regional Variations in Seasonality

\begin{tabular}{|c|c|c|c|c|c|c|c|c|}
\hline Region & $\begin{array}{c}\text { Seasonal } \\
\text { fluctuations }\end{array}$ & $\begin{array}{c}\text { Population } \\
\text { density }\end{array}$ & $\mathrm{HHI}$ & $\begin{array}{c}\text { World } \\
\text { Heritage Site }\end{array}$ & Museum & $\begin{array}{c}\text { Share of foreign } \\
\text { travelers }\end{array}$ & $\begin{array}{c}\text { Number of } \\
\text { travelers }\end{array}$ & $\begin{array}{l}\text { Region fixed effects } \\
\text { and residuals }\end{array}$ \\
\hline Canary Islands & 0.38 & 0.83 & 0.99 & 1.11 & 1.31 & 1.80 & 1.06 & 0.16 \\
\hline Balearic Islands & 3.16 & 0.85 & 0.99 & 1.17 & 1.24 & 1.95 & 1.07 & 1.25 \\
\hline Valencian Community & 1.19 & 0.85 & 1.00 & 1.10 & 1.00 & 1.28 & 1.05 & 0.95 \\
\hline Catalonia & 2.08 & 0.84 & 1.01 & 1.02 & 1.09 & 1.65 & 1.13 & 1.19 \\
\hline Andalusia & 1.40 & 0.90 & 0.99 & 1.02 & 1.02 & 1.40 & 1.13 & 0.94 \\
\hline Madrid & 0.38 & 0.76 & 1.00 & 1.06 & 1.09 & 1.44 & 1.07 & 0.28 \\
\hline Basque Community & 1.01 & 0.82 & 1.01 & 1.24 & 1.22 & 1.27 & 0.93 & 0.69 \\
\hline Region of Murcia & 1.11 & 0.88 & 0.99 & 1.20 & 1.22 & 0.98 & 0.87 & 1.02 \\
\hline Castile-Leon & 1.00 & 1.00 & 1.00 & 1.00 & 1.00 & 1.00 & 1.00 & 1.00 \\
\hline Aragon & 0.81 & 1.00 & 1.01 & 1.06 & 1.26 & 0.92 & 0.93 & 0.70 \\
\hline La Rioja & 0.98 & 0.94 & 1.00 & 1.14 & 1.77 & 0.92 & 0.81 & 0.70 \\
\hline Galicia & 1.73 & 0.90 & 1.00 & 1.08 & 1.19 & 1.01 & 0.98 & 1.49 \\
\hline Asturias & 1.98 & 0.90 & 1.00 & 1.20 & 1.33 & 0.79 & 0.90 & 1.96 \\
\hline Cantabria & 2.29 & 0.89 & 1.00 & 1.20 & 1.75 & 0.94 & 0.87 & 1.49 \\
\hline Navarre & 1.23 & 0.94 & 1.01 & 1.20 & 1.59 & 1.08 & 0.84 & 0.75 \\
\hline Castile-La Mancha & 0.72 & 1.01 & 1.00 & 1.10 & 1.06 & 0.93 & 0.93 & 0.72 \\
\hline Extremadura & 0.91 & 1.00 & 0.99 & 1.10 & 1.33 & 0.86 & 0.88 & 0.84 \\
\hline $\operatorname{Max}$ & 3.16 & 1.01 & 1.01 & 1.24 & 1.77 & 1.95 & 1.13 & 1.96 \\
\hline Min & 0.38 & 0.76 & 0.99 & 1.00 & 1.00 & 0.79 & 0.81 & 0.16 \\
\hline Max/Min & 8.39 & 1.32 & 1.02 & 1.24 & 1.78 & 2.47 & 1.40 & 11.94 \\
\hline
\end{tabular}

Note: Values are relative to those in Castile-Leon, the base region. Regions are listed in descending order of productivity as in Table 5. Seasonal fluctuations are estimated by the Gini coefficient. 


\section{Summary and Conclusions}

Tourism is an effective tool for economic development in regions with low levels of industrial development. However, seasonality leads to serious concerns among tourism authorities and businesses about its effectiveness. Evaluating seasonality's effect on local economies and identifying factors affecting seasonality are key for the sustainable development of the tourism sector and regional economies. Previous studies have found that natural and institutional factors affect seasonality, but they have not quantitatively evaluated the relative contributions of these factors to seasonality. Therefore, we first examined the contribution of peak demand and seasonality to regional productivity disparities in the Spanish accommodation sector. Then, we explored the sources of seasonality, and discussed the effectiveness of alternative policies for mitigating spatial disparities in productivity and seasonality.

The estimation results confirmed large productivity gaps among regions. Productivity in the least productive region (Extremadura) is $44(=100 \times 0.82 / 1.88)$ percent of that in the most productive region (the Canary Islands). As expected, peak demand and seasonality have a positive and negative impact on productivity, respectively. Quantitatively, peak demand has a greater impact on productivity than seasonality does, but the contribution of seasonality to regional productivity disparities is not negligible. Indeed, we found that the largest seasonal fluctuations in the Balearic Islands are 8.39 times greater than the lowest ones in the Canary Islands and Madrid. Hall and Jones' productivity accounting procedure shows that among 
factors, the number of museums, the share of foreign travelers, and natural factors contribute most to the regional variations in seasonality, followed by population density and the number of World Heritage Sites.

Our results confirm the effectiveness of a strategy of attracting tourists in the peak season based on the available records. It remains for future research to examine if this strategy is still valid in the long run. Cuccia and Rizzo (2011), for example, argue that peak-season tourism congestion could cause dissatisfaction among tourists and irreversible damage to the environment for future generations. A strategy of improving a region's attractiveness as a tourist destination is considered sustainable only if the number of travelers in the peak season does not exceed the carrying capacity of the destination.

Reducing seasonality is another option in considering the sustainability of development strategies. We found that providing climate-independent tourist attractions is most effective for that purpose. In addition, attracting business travelers has a moderate impact on reducing seasonality, particularly in urban areas. Hosting meetings, incentives, conferences, and exhibitions is a well-known example in this regard (Jones and Li 2015).

However, these policies may affect peak demand as well and, consequently, regional productivity. For instance, providing climate-independent tourist attractions would improve productivity not only through a reduction in seasonality but through an increase in peak demand. Another example is a policy aimed to attract business travelers in off-peak periods. We have 
shown that this has a positive impact on productivity, as it decreases seasonality. Nonetheless, its net impact on productivity can be negative if the same policy causes a significant reduction in the number of business travelers in the peak season. To assess the overall impact of tourism policies on regional economies in the long run, we need to identify factors affecting peak demand, and quantify their impact. The results, along with the findings of this study, will help local governments and business find a policy mix that balances improving tourist destination attractiveness and reducing seasonality for sustainable tourism-based regional development. 


\section{References}

Adler, P. and P. Adler. (2003). "Seasonality and flexible labor in resorts: Organizations, employees, and local labor markets." Sociological Spectrum. 23: 59-89.

Arellano, M. and S. Bond. (1991). "Some tests of specification for panel data: Monte Carlo evidence and an application to employment equations." Review of Economic Studies. 58: $277-297$.

BarOn, R. (1975). Seasonality in Tourism: A Guide to the Analysis of Seasonality and Trends for Policy Making. London: Economist Intelligence Unit.

Baum, T. and L. Hagan. (1999). "Responses to seasonality: The experiences of peripheral destinations.” International Journal of Tourism Research. 1: 299-312.

Benito, B., Solana, J. and P. López. (2014). “Determinants of Spanish regions’ tourism performance: A two-stage, double-bootstrap data envelopment analysis.” Tourism Economics. 20: 987-1012.

Bojanic, D. and M. Lo. (2016). “A comparison of the moderating effect of tourism reliance on the economic development for islands and other countries.” Tourism Management. 53: $207-214$

Cellini, R. and G. Rizzo. (2012). "Private and public incentive to reduce seasonality: A theoretical approach.” Economics: The Open-Access, Open-Assessment E-Journal. 6 (2012-43): 1-33. 
Ciccone, A. (2002). "Agglomeration effects in Europe.” European Economic Review. 46: 213227.

Ciccone, A. and R. Hall. (1996). "Productivity and the density of economic activity." American Economic Review. 86: 54-70.

Combes, P.P., Duranton, G. and L. Gobillon. (2008). "Spatial wage disparities: Sorting matters!" Journal of Urban Economics. 63: 723-742.

Connell, J., Page, S. and D. Meyer. (2015). "Visitor attractions and events: Responding to seasonality." Tourism Management. 46: 283-298.

Cuccia, T. and I. Rizzo. (2011). "Tourism seasonality in cultural destinations: Empirical evidence from Sicily.” Tourism Management. 32: 589-595.

Cuccia, T., Guccio, C. and I. Rizzo. (2016). "The effects of UNESCO World Heritage List inscription on tourism destinations performance in Italian regions." Economic Modelling. 53: 494-508.

De Loecker, J. (2011). "Product differentiation, multiproduct firms, and estimating the impact of trade liberalization on productivity." Econometrica. 79: 1407-1451.

Duro, J. (2016). "Seasonality of hotel demand in the main Spanish provinces: Measurements and decomposition exercises." Tourism Management. 52: 52-63.

Enright, M. and J. Newton. (2004). “Tourism destination competitiveness: A quantitative approach.” Tourism Management. 25: 777-788. 
Fernández-Morales, A. (2003). "Decomposing seasonal concentration.” Annals of Tourism Research. 30: 942-956.

Fernández-Morales, A. and M. Mayorga-Toledano. (2008). "Seasonal concentration of the hotel demand in Costa del Sol: A decomposition by nationalities.” Tourism Management. 29: 940-949.

Figini, P. and L. Vici. (2012). "Off-season tourists and the cultural offer of a mass-tourism destination: The case of Rimini.” Tourism Management. 33: 825-839.

Garrod, B. (2012). "Business tourism” in P. Robinson, ed., Tourism: The Key Concepts. New York: Routledge.

Gómez-Calero, M., Molina, J. and M. Pablo-Romero. (2014). "Exploring the effect of tourism on economic growth in the Spanish provinces and autonomous communities, 1999-2008." Tourism Economics. 20: 1117-1124.

Hall, R. and C. Jones. (1999). "Why do some countries produce so much more output per worker than others?" Quarterly Journal of Economics. 114: 83-116.

Henderson, V., Kuncoro, A. and M. Turner. (1995). “Industrial development in cities.” Journal of Political Economy. 103: 1067-1090.

Jacobs, J. (1969). The Economy of Cities. New York: Vintage.

Jang, S. (2004). "Mitigating tourism seasonality: A quantitative approach.” Annals of Tourism Research. 31: 819-836. 
Jones, C. and S. Li. (2015). "The economic importance of meetings and conferences: A satellite account approach.” Annals of Tourism Research. 52: 117-133.

Koenig-Lewis, N. and E. Bischoff. (2005). "Seasonality research: The state of the art." International Journal of Tourism Research. 7: 201-219.

Krakover, S. (2000). "Partitioning seasonal employment in the hospitality industry." Tourism Management. 21: 461-471.

Lee, J. and T. Brahmasrene. (2013). "Investigating the influence of tourism on economic growth and carbon emissions: Evidence from panel analysis of the European Union.” Tourism Management. 38: 69-76.

Lee, C.C. and C.P. Chang. (2008). "Tourism development and economic growth: A closer look at panels." Tourism Management. 29: 180-192.

Lundtorp, S., Rassing, C. and S. Wanhill. (1999). "The off-season is 'no season': The Case of the Danish island of Bornholm.” Tourism Economics. 5: 49-68.

Mathieson, A. and G. Wall. (1982). Tourism - Economic, Physical and Social Impacts. Longman: Essex.

Mazanec, J., Wöber, K. and A. Zins. (2007). “Tourism destination competitiveness: From definition to explanation?" Journal of Travel Research. 46: 86-95.

Morikawa, M. (2016). "Foreign tourists and capacity utilization in the accommodation industry." RIETI Discussion Paper Series 16-E-064. 
Murphy, P.E. (1985). Tourism: A community approach. London: Methuen.

Nadal. J., Font, A. and A. Rosselló. (2004). "The economic determinants of seasonal patterns." Annals of Tourism Research. 31: 697-711.

Ortega, B. and C. Chicón. (2013). "Determinants of regional labour productivity in the hospitality industry in Spain, 1996-2004.” Tourism Economics. 19: 393-414.

Park, S., Yaduma, N., Lockwood, A. and A. Williams. (2016). "Demand fluctuations, labour flexibility and productivity." Annals of Tourism Research. 59: 93-112.

Parrilla, J., Font, A. and J. Nadal. (2007). “Accommodation determinants of seasonal patterns." Annals of Tourism Research. 34: 422-436.

Planas, C., Roeger, W. and A. Rossi. (2010). "Does capacity utilisation help estimating the TFP cycle?” European Economy, Economic Papers 410.

Pratt, S. (2015). "The economic impact of tourism in SIDS.” Annals of Tourism Research. 52: $148-160$.

Roget, F. and X. González. (2006). “Occupancy level and productivity in rural tourism establishments: The case of Galicia, Spain.” Tourism Economics. 12: 279-289.

Roodman, D. (2009). "How to do xtabond2: An introduction to difference and system GMM in Stata." Stata Journal. 9: 86-136. 
Saló, A., Garriga, A., Rigall-I-Torrent, R., Vila, M. and J. Sayeras. (2012). “Differences in seasonal price patterns among second home rentals and hotels: Empirical evidence and practical implication.” Tourism Economics. 18: 731-747.

Such, M. and M. Zamora. (2006). "Spanish productivity: A regional approach.” Annals of Tourism Research. 33: 666-683.

Syverson, C. (2011). "What determines productivity?” Journal of Economic Literature. 49: 326365.

Terkenli, T. (2005). "Human activity in landscape seasonality: The case of tourism in Crete." Landscape Research. 30: 221-239.

Terry, W. (2016). "Solving seasonality in tourism? Labour shortages and guest worker programmes in the USA.” Area. 48: 111-118.

Van Beveren, I. (2012). “Total factor productivity estimation: A practical review.” Journal of Economic Surveys. 26: 98-128.

Vergori, A. (2012). "Forecasting tourism demand: The role of seasonality." Tourism Economics. 18: 915-930.

Wooldridge, J. (2010). Econometric Analysis of Cross Section and Panel Data 2nd Edition. Cambridge, MA: The MIT Press 
World Travel and Tourism Council (WTTC). (2015). The Economic Impact of Travel \& Tourism 2015. Retrieved on March 16, 2016 from http://www.wttc.org/research/economicresearch/economic-impact-analysis/. 